\title{
Botanische Bollwerke
}

Können Pflanzen Krebs bekommen? Das ist nicht zuletzt eine

Frage der Definition. Zwar wachsen Neoplasien auch in Pflanzen, sie sind aber seltener und tendenziell weniger bösartig als bei Menschen oder Tieren. Ein Grund dafür: Pflanzenzellen sind unbeweglich, sie sind in starren Zellwänden verankert - das verhindert Metastasen. Auch scheint die Maschinerie zur Unterdrückung von Tumoren schlagkräftiger zu sein: Beispielsweise verfügen einige Gewächse über besonders viele Kopien von Tumorsupressorgenen. Zudem kommen Pflanzen offenbar mit Zellvermehrungen allgemein besser klar - sie werden einfach größer, ohne, dass Geschwulste entstehen. Und: In der Fauna werden Neoplasien meist durch Bakterien, Viren oder Pilze ausgelöst; Tumoren aufgrund von spontanen Mutationen sind selten. Bezeichnende Ausnahme: Die Tabakpflanze!

Ein häufiger Pflanzentumor ist der Gallapfel. Galläpfel werden traditionell für verschiedene Zwecke genutzt - wofür jedoch nicht?

A Zum Herstellen von Schreibtinte

B Zum Entbittern von Wein

C Zum Gerben von Leder

\section{Der Buchstabe der richtigen Antwort ist}

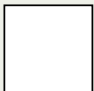

\section{Name}

Straße, Nr.

\section{PLZ, Ort}

Was ich noch sagen wollte ...

Coupon bitte ausfüllen und abschicken an Springer Medizin Verlag $\mathrm{GmbH}$ Redaktion Im Focus Onkologie - Quiz 3/2017

Aschauer Straße 30, 81549 München

Oder senden Sie uns eine E-Mail an kim.jene@springer.com

Einsendeschluss: 21.04.2017

\section{Und das können Sie gewinnen ...}

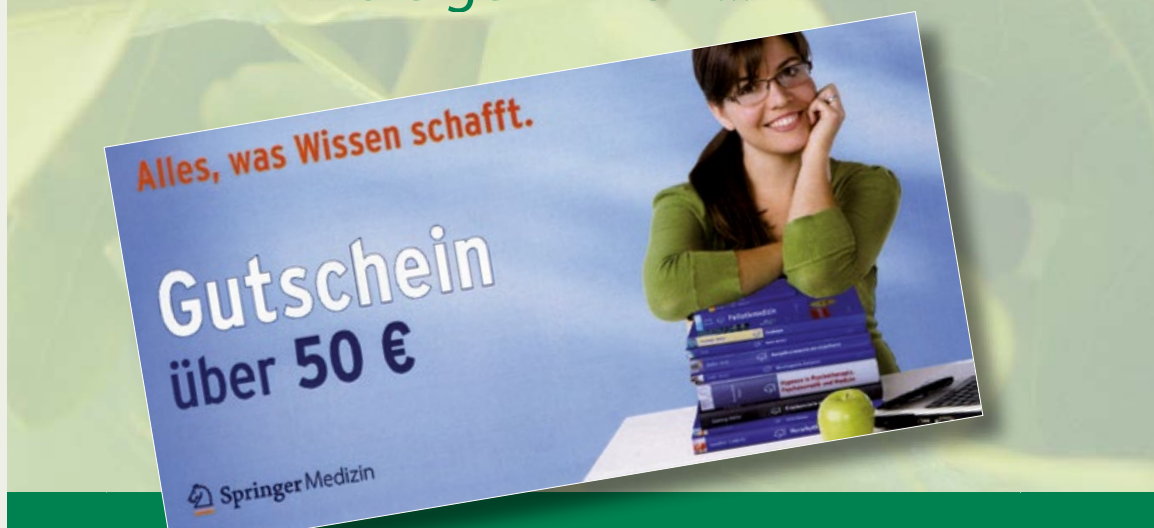

Unter den richtigen Einsendungen verlosen wir drei Gutscheine über 50 Euro, die Sie für ein beliebiges Springer-Buch einlösen können.
Lösung des Quiz 12/2016 Richtig war: B

Die Gewinne gehen an: J. Winter, Dinkelsbühl R. Juncken, Berlin B. Tielkes, Ahaus Herzlichen Glückwunsch! 